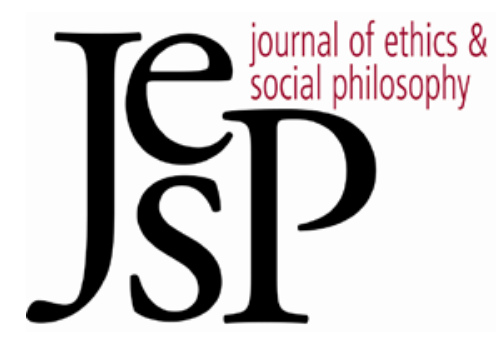

\title{
ON the Nature, Existence AND Significance OF Organic UNITIES
}

BY MiCHAEL J. ZIMMERMAN

JOURNAL OF ETHICS \&SOCIAL PHILOSOPHY

VOL. 8, NO. 3| JANUARY 2015 URL: WWW.JESP.ORG COPYRIGHT (C MICHAEL J. ZIMMERMAN 2015 


\section{On the Nature, Existence and Significance of Organic Unities \\ Michael J. Zimmerman}

\section{$\mathrm{I}$} N CHAPTER I OF PRINCIPLA ETHICA, G. E. Moore introduces what he calls the principle of organic unities, ${ }^{1}$ which he formulates as follows: "The value of a whole must not be assumed to be the same as the sum of the values of its parts." 2 To emphasize the significance of this principle, he puts his statement in italics. Not only Moore but many other philosophers have deemed the principle to be of fundamental importance to ethics. I have doubts on that score, which in this paper I try to explain and justify.

In Section 1, I provide a provisional reformulation of the principle of organic unities and contrast such unities with mere sums of value. In Section 2 , I undertake some groundwork in order to arrive at an account of the partwhole relation with which the principle of organic unities is concerned. In so doing, I provide some further reformulations of that principle. In Section 3, I briefly discuss the isolation method that Moore proposes for determining the value of something, and then, in Section 4, I begin an extended discussion of a particular example of an alleged organic unity, namely, Schadenfreude. I explain why some philosophers claim that such pleasure constitutes an organic unity, but I also present reasons for denying this claim. In Section 5, I pursue one of these reasons in particular, a reason that appeals to the concept of what I call evaluative inadequacy, and, in Section 6, I seek to motivate this appeal by drawing on the relation between value and fitting attitudes. In so doing, I provide still further reformulations of the principle of organic unities. In Section 7, I entertain objections to my account of Schadenfreude, one of which requires one final reformulation of the principle of organic unities, and then, in Section 8, I discuss the more general objection that, even if my reasons for denying that Schadenfreude constitutes an organic unity are cogent, these reasons do not extend to other alleged organic unities, such as the related phenomenon of Mitleid. In the final section, I briefly address the significance of the debate about whether the principle of organic unities is true.

\section{Organic Unities and Mere Sums}

The kind of value with which Moore is concerned is what he calls intrinsic value. Accordingly, the principle he has in mind may be rendered more precisely as follows:

POU 1: The intrinsic value of a whole must not be assumed to be the same as the sum of the intrinsic values of its parts.

\footnotetext{
1 Moore (1903: xi), (1993: 36).
}

2 Moore (1903: 28), (1993: 79). 
The underlying conception of an organic unity is of course this:

OU 1: $\quad x$ is an organic unity $=_{\mathrm{df}}$ the intrinsic value of $x$ is not the same as the sum of the intrinsic values of its parts.

The first example of an organic unity given by Moore is that of consciousness of some beautiful object, which he claims to be of great intrinsic value, even though neither consciousness itself nor the object itself holds much value. ${ }^{3}$ The literature since Principia Ethica abounds with other examples. Many of them concern complex cases involving either joy or suffering. One such case, to which I will be paying close attention, is that of Schadenfreude, or malicious pleasure. Whereas pleasure itself strikes many as being intrinsically good, malicious pleasure seems not to be so good, and, for reasons to be discussed shortly, many hold that the intrinsic value of such pleasure cannot simply be the same as the sum of the intrinsic values of its parts. Similarly for Mitleid, the kind of fellow suffering that is distinctive of true compassion, to which I will also pay some attention: Whereas suffering itself strikes many as being intrinsically bad, compassion seems not to be so bad, and, again, many hold that such suffering constitutes an organic unity.

In his discussion of organic unities, Roderick Chisholm draws a distinction between such wholes and what he calls mere sums of value. ${ }^{4}$ There are six basic types of such sums: unmixed goods (that is, good wholes that have no bad part), mixed goods (that is, good wholes that have some bad part), unmixed evils, mixed evils, unmixed neutrals and mixed neutrals. In the mixed cases, either the good parts outweigh the bad parts (resulting in a mixed good), or the bad parts outweigh the good parts, or the good and bad parts counterbalance one another. The values of organic unities, however, cannot be accounted for in terms of outweighing or counterbalancing. On the contrary, the key concept here is that of defeat. ${ }^{5}$ By way of example, consider a particular case of Schadenfreude: John's being pleased at Mary's pain. For reasons to be discussed later, Chisholm holds that any such instance of Schadenfreude constitutes an organic unity. If John's being pleased at Mary's pain is good, but not as good as that part of it that consists simply in his being pleased, then, Chisholm would say, the value of this part has been partially defeated by the whole. I will call such defeat mitigation. However, if John's being pleased at Mary's pain is not good at all, then the value of that part of it that consists simply in his being pleased has been totally defeated by the whole. I will call such defeat nullification. Finally, if John's being pleased at Mary's pain is positively evil, then, I will say, the goodness of the part in question has been defeated in such a way as to have been inverted by the whole.

\footnotetext{
${ }^{3}$ Moore (1903: 28), (1993: 79-80).

${ }^{4}$ Chisholm (1986: 74-75).

${ }_{5}$ Chisholm (1986: 85ff.) notes that the values of some organic unities are to be attributed to enhancement or aggravation rather than defeat.
} 
Along with many others, I find the view that Schadenfreude is positively evil to be intuitively plausible. For the purposes of this paper, I will presuppose this view. The question I wish to address is this: Should we agree that the evil of Schadenfreude involves the kind of inversion of goodness diagnosed by Chisholm?

\section{Groundwork}

In order to answer this question, we will have to do some groundwork.

First, the kind of value with which we are concerned is the value that something has for its own sake, rather than for the sake of something else to which it may be related in some way. Moore uses the term "intrinsic value" in this context because he takes such value to supervene entirely on (some of) the intrinsic properties of its bearers. This is a controversial view. A more neutral term that has recently come to be used to refer to such value is "final value." This is the term that I will henceforth use. I should therefore revise my earlier statement of the principle of organic unities and the concomitant conception of an organic unity as follows:

POU 2: The final value of a whole must not be assumed to be the same as the sum of the final values of its parts.

OU 2: $x$ is an organic unity $=_{\mathrm{df}}$ the final value of $x$ is not the same as the sum of the final values of its parts.

Second, the particular kind of final value that is of concern here is impersonal. It has to do with how things are "in the world," so to speak; it is not the kind of value with which personal welfare has to do. As a possible example of this contrast, consider Schadenfreude. I have assumed that such pleasure is positively evil. What I mean by this is that any instance of such pleasure is finally bad as far as the world is concerned - that the world is, insofar forth, a worse place for the occurrence in it of Schadenfreude. Saying so is consistent with also saying that a person is, insofar forth, better off for the occurrence of Schadenfreude in his life - that such pleasure enhances his welfare.

Third, the clause "insofar forth" is crucial to what I have just said. Suppose, for example, that the world is, insofar forth, a better place for the occurrence in it of non-malicious pleasure. Then such pleasure will be finally good, in the sense that concerns me. But suppose that, on some occasion, the occurrence of such pleasure causes a catastrophe that makes the world all things considered worse than it would otherwise have been. Then such pleasure will, on that occasion, be non-finally bad - in this case, bad as a means. That does not alter the fact that it is nonetheless finally good - good as an end.

Fourth, the question arises as to what kind of thing can have final value (as far as the world is concerned; henceforth, I will omit this qualification, although it will always be implicit in what I say). Some recent discussions of 
organic unities do not address this question, ${ }^{6}$ which is unfortunate, since it is hard to make sense of talk of the values of "parts" and "wholes" without having first determined to what ontological category these parts and wholes belong. Moore himself is a pluralist on this issue. On different occasions he attributes final value to individual objects, to the existence of individual objects, to types of individual objects and to states of individual objects. ${ }^{7}$ Some recent discussions have been similarly liberal; ${ }^{8}$ others have been more conservative. W. D. Ross, for example, ascribes final value only to facts, as does Noah Lemos (although they may not have precisely the same kind of thing in mind when writing of "facts"). ${ }^{9}$ Chisholm, on the other hand, ascribes such value only to states of affairs, as does Fred Feldman. ${ }^{10}$ If we keep in mind that the kind of value in question is that which makes the world better (or worse), then, I think, there is good reason to adopt some such conservative account of the bearers of value. Perhaps individual objects can have some kind of value - indeed, they surely do; not only does it make sense, but it is surely correct to say of some individual objects (including people) that they have value. But if these individual objects contribute to the value of and in the world, they do so by way of their being either in some kind of state or involved in some kind of event. In my view, the kind of state or event at issue is not a state of affairs of the sort that Chisholm and Feldman have in mind, one that exists necessarily but may or may not obtain. Rather, it is a type of concrete entity that exists or occurs contingently. I say this for two reasons (both contestable, of course): 1) Since it is such entities that can enter into causal relations, we can give a simple, straightforward interpretation of the claim that something has value either as a means or as an end. For example, if my sending you flowers makes you happy, then, it is plausible to say, my sending you flowers is good as a means precisely because it causes your being happy, which is good as an end. 2) As Chisholm himself acknowledges, it is awkward to ascribe final value to states of affairs that do not obtain. As he says, "Everyone being happy is not a state of affairs that obtains and therefore we are not likely to say of it that it is good. We would be more likely to say of it that it would be good if it were to obtain." ${ }_{11}$ But even that does not seem quite right. What would be good if on some occasion everyone were happy is not the abstract state of affairs of everyone being happy that happened then to obtain but rather the concrete state that instantiated that state of affairs on that occasion.

Fifth, the question then arises as to how concrete states and events are to be individuated. Here, there are two possibilities: coarsely (à la Davidson ${ }^{12}$ )

\footnotetext{
6 See, e.g., Hurka (1998); Dancy (2004, ch. 10).

7 See, respectively, Moore (1903: 3), (1993: 55); (1903: 196), (1993: 244); (1922: 260); and (1903: 195), (1993: 243).

8 See, e.g., Kagan (1998) and Rabinowicz and Rønnow-Rasmussen (1999).

${ }^{9}$ Ross (1930: 112-13); Lemos (1994: 23).

${ }_{10}$ Chisholm (1986: 60, 73); Feldman (2000: 321).

${ }_{11}$ Chisholm (1968-69: 23).

12 Davidson (1980: 163ff.).
} 
and not so coarsely. One reason (again contestable) for opting for the latter is this: To make sense of the claim that John's being pleased is finally good while his being pleased at Mary's pain is finally bad, we should hold these states to be distinct.

Sixth, we should distinguish between parts and proper parts. For any things $a$ and $b$ that can be or have parts (whether individual objects, states or some other kind of entity), $a$ is a proper part of $b$ just in case $a$ is a part of $b$ but $b$ is not a part of $a$. It is clear that it is with proper parts in particular that Moore is concerned when he proposes his principle of organic unities. And so, for the sake of accuracy, we should once again revise our formulation of this principle and the concomitant conception of an organic unity, as follows:

\footnotetext{
POU 3: The final value of a whole must not be assumed to be the same as the sum of the final values of its proper parts.

OU 3: $x$ is an organic unity $=_{\mathrm{df}}$ the final value of $x$ is not the same as the sum of the final values of its proper parts.
}

Finally, we must address the question, crucial in the present context, of how precisely to account for the part-whole relation as it pertains to states and events. By far the most thorough treatment of this issue with which I am familiar is that provided by Judith Thomson.13 Her account is attractive, inasmuch as it mirrors what we would normally want to say about the partwhole relation as it pertains to individual objects. Imagine a ball divided into two equal halves that remain intact. The ball is a whole; the halves are parts of this whole. Now imagine someone going for a run from A to B and back. The entire run, Thomson says, is a whole; one part of it is the run from A to $B$, while another part is the run from B to A. ${ }^{14}$ Attractive though it is, I do not see how to apply this account to the examples of (alleged) organic unities offered by Moore and others. How, for example, does it yield the claim that John's being pleased is a part of his being pleased at Mary's pain? More promising, for present purposes, is the kind of account advocated by Jaegwon Kim, according to which a state (or event) consists in the exemplification by some individual (or individuals) of some property (or relations) at (or during) some time.15 Such a state can be perspicuously designated by an expression of the form $[x, P, t$, which serves to indicate explicitly the state's constituents $-x$ being the individual concerned, $P$ the property and $t$ the time. For example, if Dave drinks some water at time $t_{1}$, then a state, $S$, of the form [Dave, drinking water, $t_{1}$ ] occurs. Likewise, if Fiona eats some fish at time $t_{2}$, then a state, $S^{\prime}$, of the form [Fiona, eating fish, $t_{2}$ ] occurs. Moreover, states can combine in such a way as to beget other states. For example, if both $S$ and $S^{\prime}$ occur, then $\left[S \& S^{\prime}\right]$ also occurs (that is, a state of the form

\footnotetext{
13 Thomson (1977).

14 Ibid.: 109.

$15 \operatorname{Kim}(1976)$.
} 
[[Dave, drinking water, $\left.t_{1}\right] \&$ [Fiona, eating fish, $t_{2}$ ]] also occurs). We may call $S$ and $S^{\prime}$ the components of [S\&S $]$.

It is important to note that states, so construed, can be indeterminate, in the sense that their constituent property or properties may not be fully specific. (The property of drinking water does not specify the quantity or quality of water drunk; so, too, with the property of eating fish.) Because this is so, many states will turn out to be what I will call the ontological descendants of other states, which are their ontological ancestors. An ontological ancestor of a state, $S$, is a state in virtue of which $S$ occurs, in the sense illustrated by the following example. Suppose that on some occasion John is pleased. Then a state, $S 1$, of the form [John, being pleased, $t$ ] occurs. But if, more particularly, John is on that occasion pleased at something - Mary's pain, say - then there will be another state, $S 2$, of the form [John, being pleased at Mary's pain, $t$ ], in virtue of which $S 1$ occurs; $S 1$ will be an ontological descendant of $S 2$, the latter an ontological ancestor of the former. On the basis of this observation, I propose that we say the following: 1) In the case of noncombinative states, state $S$ is identical with state $S^{\prime}$ just in case $S$ and $S^{\prime}$ have exactly the same constituents and exactly the same ontological ancestors. (Notice that this allows for the possibility that two distinct noncombinative states have exactly the same form. For example, if John experiences several distinct pleasures at $t$, then several states of the form [John, being pleased, $t$ ] will occur. If this happens, it will be because the states in question have distinct ancestors.) 2) In the case of combinative states, $S$ is identical with $S^{\prime}$ just in case $S$ and $S^{\prime}$ have exactly the same components. 3) $S$ is a proper part of $S^{\prime}$ just in case either (a) $S^{\prime}$ is an ontological ancestor of $S$, or (b) $S^{\prime}$ is a combinative state and $S$ is one of its components, or (c) $S^{\prime}$ is a combinative state and one of its components is an ontological ancestor of $S .16$

\section{The Isolation Method}

In Principia Ethica, Moore appeals to a single method for answering the dual question, "What things have intrinsic value, and in what degrees?" He describes the method as follows:

In order to arrive at a correct decision on the first part of this question, it is necessary to consider what things are such that, if they existed by themselves, in absolute isolation, we should yet judge their existence to be good; and, in order to decide upon the relative degrees of value of different things, we must similarly consider what comparative value seems to attach to the isolated existence of each. ${ }^{17}$

This passage is promising but problematic.

Lemos has distinguished two versions of the isolation method.18 He calls Moore's version "ontological isolationism" and declares it "not very helpful."

16 This is only a rough rendition of my view. For further details, see Zimmerman (2001: 52$60)$.

17 Moore (1903: 187), (1993: 236).

18 Lemos (1994: 10-11). 
He is surely right about this, since it is strictly impossible for anything to exist by itself, in total isolation. In particular, a state of the form $[x, P, t]$ can exist only if each of $x$, and $P$, and $t$ and their respective parts exists, not to mention whatever else might exist necessarily.

Lemos holds, and I agree, that the version of the isolation method that Moore should have invoked is what he (Lemos) calls "intentional isolationism." In order to gauge the final value of a state of the form $[x, P, t]$, what we must do is consider or contemplate this state as such, that is, qua having the form $[x, P, t]$, and we must focus our attention on $i t$, so as to exclude from our consideration any other states to which it may in some way be related, since otherwise our evaluation of it may be contaminated by our awareness of these other states. In this way we can hope to succeed in doing what I take it Moore was at bottom trying to do, namely, evaluate a state "in its own right," without reference to its context or consequences.

\section{The Value of Schadenfreude}

We are now in a position to assess the final value of Schadenfreude. Consider $S 2$ again, a state whose form is [John, being pleased at Mary's pain, $t$ ]. I have assumed that such a state is finally bad. What parts does $S 2$ have whose values might account for its value? One such part has already been identified: $S 1$, a state whose form is [John, being pleased, $t$ ]. Is there any reason to declare it finally bad? It would seem not. On the contrary, contemplation of $S 1$ as such might well prompt one to declare it finally good. This is the verdict of Chisholm and Lemos and, possibly, of Moore as well. ${ }^{19}$ Is there any other part of $S 2$ whose value might outweigh the value of $S 1$ in such a way that would allow us to declare $S 2$ finally bad without declaring it to be an organic unity? Here it might be thought that a state of the form [Mary, being in pain, t] would do the trick, but there is a problem. As Chisholm and Lemos note, it could be that Mary is actually not in pain; it is just that John believes that she is. ${ }^{20}$ If so, then no state of the form [Mary, being in pain, $t$ ] occurs, and yet we would still be dealing with a case of genuine Schadenfreude, one which (I am assuming) should be declared finally bad. It might seem, moreover, that there are no other parts of $S 2$ whose values could help account for its value. If that is right, then we must indeed declare this and all other such instances of Schadenfreude to be organic unities.

But this is to move too fast. There are several ways in which one might seek to resist the conclusion that $S 2$ constitutes an organic unity.

a.

First, one might look for further parts of $S 2$ whose values, along with the value of $S 1$, might account for its value. Given that $S 2$ has parts, it counts as

19 See Chisholm (1986: 76-77) and Lemos (1994: 36). Moore's view about the value of pleasure is more complicated. See Moore (1903: 208ff.), (1993: 257ff.).

20 Chisholm (1986: 76); Lemos (1994: 36). 
a "whole" in Moore's sense. Since we are working under the assumption that this state is finally bad, let us assign it the particular value of -10 . (This number is plucked out of thin air, of course, but it will help for the purpose of illustration.) At one point, Moore calls this value the value that $S 2$ has "on the whole," and he distinguishes this value from the value that $S 2$ has "as a whole" as follows: "[T] he value which a thing possesses on the whole may be said to be equivalent to the sum of the value which it possesses as a whole, together with the intrinsic values which may belong to any of its [proper] parts." ${ }_{21}$ Suppose that we assign a value of +5 to $S 1$ and a value of 0 to any and all other proper parts of $S 2$. Then two points follow: 1) $S 2$ constitutes an organic unity, since its value $(-10)$ is not equivalent to the sum of the values of its proper parts $(+5) .2)$ The value of $S 2$ on the whole $(-10)$ is equivalent to the sum of the values of its proper parts $(+5)$ together with its value as a whole $(-15)$. But once the value of $S 2$ as a whole has been identified, the suspicion may arise that this value could after all be attributable to some of its proper parts that have hitherto escaped notice. What might these parts be? Well, one possibility is Mary's pain. Just now, in keeping with Chisholm and Lemos, I dismissed this possibility, on the grounds that Mary might in fact not be in pain at all. But perhaps this was too hasty. After all, Mary's pain, actual or not, is the intentional object of John's pleasure, and perhaps such an object should be counted as a part of the whole.22 If it should, and if its final value were -15 , then the whole would be a mere sum after all and not an organic unity.

Another possible candidate for a hidden part whose value, along with the values of other parts, might account for the value of $S 2$ is this: a state of the form [John, experiencing an inappropriate emotion, $t]$. After all, it is precisely because John's pleasure in this case is inappropriate that we are moved to declare it finally bad. Now, Chisholm and Lemos reject this suggestion, too, ${ }^{23}$ but it might seem to have some plausibility.24 (I will return to this suggestion in Section 8.)

Yet another possible candidate for a hidden part that might play the role we are looking for is the relation between, or arrangement of, the various other parts that have been identified. Chisholm and Lemos would once again reject this suggestion, as do other proponents of organic unities. For example, W. D. Ross, who is one such proponent, has this to say:

We have no right to assume that the value of a whole is precisely equal to the sum of the values of its elements taken separately. It may owe some of its value to the co-presence of certain of its elements in certain relations to one another; and this co-presence of its elements cannot fairly be called another element and thus taken to justify us in saying that the value of the whole is the sum of the values of its elements. 25

${ }^{21}$ Moore (1903: 214), (1993: 263).

22 Cf. Olson (2004: 41).

23 See Chisholm (1986: 77); Lemos (1994: 36, n. 11) and (2010: 38).

${ }^{24}$ Cf. Zimmerman (2001: 138).

25 Ross (1930: 72). 
However, while this may be a reasonable thing to say, when the "wholes" and "elements" at issue are individual objects - for, whatever should count as a part of an individual object, surely a relation cannot do so - the issue becomes murkier when we are dealing with states. Although relations cannot be parts of concrete states any more than they can be parts of individual objects, their instances might be.

Now, I am certainly not insisting that any of these appeals to hidden parts succeeds in showing that $S 2$ is not an organic unity. I am simply pointing out that they have some plausibility and warrant further investigation. Of course, these appeals are difficult (indeed, the first is impossible) to reconcile with the account of the part-whole relation that I proposed earlier, but perhaps the lesson to draw from this is not that $S 2$ is an organic unity but rather that my account of the part-whole relation as it pertains to states is incorrect. It would, of course, be incumbent on anyone who rested his case against organic unities on the basis of such an appeal to hidden parts to provide an acceptable alternative account of the part-whole relation, but perhaps this could be done. (Another move would be to dismiss the entire enterprise of providing such an account as misguided, on the basis of the claim that $S 2$ is finally bad but not the sort of thing that can have proper parts at all, let alone proper parts whose values are at odds with its value.)

b.

A second way in which one might seek to resist the claim that $S 2$ is an organic unity is to invoke an account of final value according to which the final value of a state can depend on the context in which it occurs. One might claim, for example, that $S 1$ is finally bad after all, given that it occurs in the context of $S 2.26$ Such a "conditionalist" account is of course inconsistent with the view that final value supervenes only on the intrinsic properties of its bearers, but, as I noted above, this is a contentious view anyway. It is also true that such an account is hard to reconcile with the claim that intentional isolationism is the proper method of computing final value, but perhaps some other method could serve instead.

c.

There is a third way to resist the claim that $S 2$ is an organic unity, one that I have proposed in previous work, and one that neither presupposes an alternative account of the part-whole relation nor repudiates intentional isolationism as the proper method of computing final value. My proposal depends crucially on the concept of evaluative inadequacy.

${ }^{26}$ Cf. Hurka (1998: 311-12); Olson (2004: 40-41). 


\section{Evaluative Inadequacy}

I said in the last section that contemplation of $S 1$ as such, i.e., qua a state whose form is [John, being pleased, $t$ ], might well prompt one to declare it finally good, even if contemplation of its ontological ancestor $S 2$ as such, i.e., qua a state whose form is [John, being pleased at Mary's pain, $t$ ], leads one to declare it finally bad. I now wish to suggest that this seemingly plausible pair of verdicts is mistaken. If one holds, as I have been assuming, that $S 2$ is finally bad, then one ought not to declare $S 1$ finally good. Contemplation of $S 1$ itself should, I believe, issue in a different verdict.

But what should this verdict be? Surely, if we stick to the method of intentional isolationism, there is no good reason to declare $S 1$ finally bad; on the contrary, such a verdict would betray the failure to isolate the part from the whole. So, too, there would seem to be no good reason to declare S1 finally neutral. What other verdict remains?

The verdict that remains is that $S 1$ is neither finally good nor finally bad nor finally neutral and thus has no final value. It is, as I will put it, evaluatively inadequate. Almost all writers on final value appear to have assumed that, if some ontological category is such that something that falls into that category can have final value, then everything that falls into it does in fact have final value. But this seems to me to be a mistake. Even if, as I have assumed, final value is to be ascribed only to states, it does not follow that it is to be ascribed to all states, and I do not think it should be. Given that $S 2$ is finally bad, we should declare $S 1$ evaluatively inadequate.

It must be acknowledged that the move to evaluative inadequacy does not put the principle of organic unities, as most recently formulated, into question. The most recent formulation was this:

POU 3: The final value of a whole must not be assumed to be the same as the sum of the final values of its proper parts.

If (a) $S 2$ has a final value, (b) $S 1$ is a proper part of $S 2$, and (c) $S 1$ has no final value, then POU 3 is confirmed rather than disconfirmed. But I take it that, once the possibility of a state's lacking final value altogether has been acknowledged, POU 3 does not capture the principle that Moore was really after. We should instead reformulate that principle as follows:

POU 4: The final value of a whole must not be assumed to be the same as the sum of the final values of those of its proper parts that have such value.

The conception of an organic unity must of course be revised accordingly:

OU 4: $x$ is an organic unity $=_{\mathrm{df}}$ the final value of $x$ is not the same as the sum of the final values of those of its proper parts that have such value.

My claim is that, given the evaluative inadequacy of $S 1$, there is no reason to declare $S 2$ an organic unity, regardless of what final value is ascribed to it. 
A problem still remains, however. Suppose not only that $S 1$ occurs in virtue of $S 2$ but also that $S 2$ occurs in virtue of $S 3$, a state whose form is [John, being pleased at Mary's pain while sitting, $t$ ], which itself occurs in virtue of $S 4$, a state whose form is [John, being pleased at Mary's pain while sitting and smoking a cigar, $t$ ]. Earlier, I assigned a final value of -10 to $S 2$. It is plausible to assign this same value to each of $S 3$ and $S 4$. But $S 4$ has $S 3$ and $S 2$ as proper parts. Since the sum of the values of these parts is $-20 \mathrm{ra}$ ther than -10 , the move to evaluative inadequacy gives us no reason after all to reject POU 4. Even if this move allows us to deny that $S 2$ is an organic unity, it does not permit such a denial in the case of $S 4$.

The solution to this problem, one that several philosophers have recognized, ${ }^{27}$ is to invoke the notion of basic final value. In the example, we may assume that $S 2$ is basically finally bad, whereas $S 3$ and $S 4$, though finally bad, are not basically so. There has been some discussion regarding how best to analyze the concept of basic final value. As I see it, the notion of evaluative inadequacy yields a simple, straightforward and attractive analysis. For a state to have basic final value is for it to have final value while none of its proper parts has such value, i.e., all of its proper parts are evaluatively inadequate. 28 This solution requires yet another reformulation of the principle of organic unities in order to capture what Moore was presumably after:

POU 5: The final value of a whole must not be assumed to be the same as the sum of the basic final values of those of its proper parts that have such value.

And, again, the conception of an organic unity must of course be revised accordingly:

OU 5: $x$ is an organic unity $=_{\mathrm{df}}$ the final value of $x$ is not the same as the sum of the basic final values of those of its proper parts that have such value.

\section{Motivating the Appeal to Evaluative Inadequacy}

Even if what I have just said provides a way of declaring such instances of Schadenfreude as $S 2$ finally bad without resorting to the principle of organic unities, the question remains why we should endorse this approach. My answer is (a) that invoking the concept of evaluative inadequacy in the context of Schadenfreude is intuitively appealing; (b) that this concept has application to a wide variety of contexts, not just to Schadenfreude, and so its invocation in that particular context should not be regarded as ad hoc; and (c) that the account of basic final value that I have proposed in terms of this concept has the flexibility needed to accommodate all axiologies.

27 See Harman (1967), Quinn (1974) and Feldman (2000), among others.

28 This account is actually too simple. It ignores the apparent fact that every state has states of shorter duration as proper parts. I will not pursue this complication here. See Zimmerman (2001: 157 ff.). 
a.

The reason that I claim that invoking the concept of evaluative inadequacy in the context of Schadenfreude is intuitively appealing is this: If we hold that a state such as $S 2$ is finally bad, then it is very hard to see why we should think its occurrence involves the occurrence of anything that is finally good. The difficulty can be brought out by noting a relation between final value and fitting attitudes, one that has been endorsed by many philosophers, including some, such as Chisholm and Lemos, who accept the principle of organic unities. The relation in question is this: If something is finally good, then it is fitting for anyone who contemplates it as such to have some favorable attitude toward it for its own sake; likewise, if something is finally bad, then it is fitting for anyone who contemplates it as such to have some unfavorable attitude toward it for its own sake. ${ }^{29}$ But is there anything to celebrate when Schadenfreude occurs? I cannot see that there is. In particular, when one contemplates a state of the form [John, being pleased, $t$ ] as such, it does not seem fitting to have a favorable attitude toward it for its own sake. Nor, I hasten to add, does it seem fitting to have an unfavorable or indifferent attitude toward it for its own sake. The stance that it would seem fitting to take is to withbold any such attitude. Given that a state of the form [John, being pleased, $t$ ] can occur not only as a part of some innocent pleasure (which we may assume to be finally good) but also as a part of some malicious pleasure (which we have been assuming to be finally bad), one should, I believe, refrain from directing any particular attitude toward such a state as such. The idea that the goodness of pleasure as such is somehow inverted when it is contained in the wider context of Schadenfreude strikes me as decidedly odd. As others have remarked, embracing this idea seems to involve a kind of "evaluative schizophrenia" that is quite unappealing. ${ }^{30}$ Invoking the concept of evaluative inadequacy provides a principled way of avoiding such schizophrenia.

b.

The concept of evaluative inadequacy also has application in other contexts. Consider a very simple version of hedonism, one according to which only states of pleasure are finally good and no state of pleasure (even of malicious pleasure) is finally bad or finally neutral, and the precise final value of a state of pleasure is determined simply by multiplying the duration of pleasure involved by its degree of intensity. For example, on this theory a state of the form [John, being pleased $\left.d_{d=10, i=5}, t\right]$ has a final value of +50 , as does a state of the form [John, being pleased $\mathbf{d}_{\mathbf{d}=10, \mathrm{i}=5}$ at Mary's pain, $t$ ]. Notice that states of each of these forms would have as a proper part a state of the form [John, being pleased, $t$ ], and so the question arises: What value should be assigned

29 Cf. Brentano (1969: 18); Broad (1930: 283); Ross (1939: 275-76); Ewing (1948: 152); Chisholm (1986: 52); Lemos (1994: 12, 15). The relation is challenged in Bykvist (2009).

30 Brännmark (2001: 227); Olson (2004: 42). 
to such a state? One answer that I find attractive is: none. It seems reasonable to hold that the constituent property of such a state is too thin - it is insufficiently rich - to warrant any assignment of value. If so, the theory should declare it evaluatively inadequate. By the same token, if all it takes for there to be final goodness is pleasure of some determinate duration and degree of intensity, then a state of the form [John, being pleased $d_{d=10, i=5}$ at Mary's pain, $t$ ] is thicker or richer than is strictly necessary for the assignment of final value. On the present theory, such a state is evaluatively superfluous. It is those states that are neither evaluatively inadequate nor evaluatively superfluous that have basic final value. Those that are evaluatively inadequate have no such value; those that are evaluatively superfluous have such value, but only nonbasically.

c.

This account of basic final value can accommodate all axiologies. This is so because it itself makes no axiological commitments. For example, the simple version of hedonism just mentioned deems a state of the form [John, being pleased, $t$ ] to be evaluatively inadequate, a state of the form [John, being pleased $\left._{\mathrm{d}=10, \mathrm{i}=5}, t\right]$ to be basically finally good and a state of the form [John, being please $d_{d=10, i=5}$ at Mary's pain, $\left.t\right]$ to be evaluatively superfluous (and, in particular, non-basically finally good). A more complex version of hedonism might deem states of either of the first two forms to be evaluatively inadequate, while declaring a state of the third form basically finally bad. And, of course, other versions might yield yet other verdicts. In general, one can envision a gamut of axiologies, ranging from the extremely atomistic (according to which all states have final value, and so none are evaluatively inadequate while many are evaluatively superfluous) to the extremely holistic (according to which the only state that at any time has final value is the entire actual world, all proper parts of it being evaluatively inadequate while nothing is evaluatively superfluous). I strongly suspect that the correct axiology lies somewhere in between these extremes, but it is not my purpose here to pursue this point.

\section{Objections}

Although I consider the appeal to evaluative inadequacy to be well motivated for the reasons just given, I recognize that it may nonetheless seem problematic for other reasons. In this section I consider four objections to the account that I have proposed.

a.

I have said that the idea that the goodness of pleasure as such is inverted when it is contained in the wider context of Schadenfreude involves an odd kind of schizophrenia, but such a characterization of it may seem unduly de- 
rogatory. After all, inversion is simply one mode of defeat, along with mitigation and nullification. Perhaps it is an especially dramatic mode, but so what? Defeat in general is a well-respected concept that has application in other contexts, so why object to its application in the present context?

I concede that there are contexts, both ethical and otherwise, in which some concept of defeat would seem applicable, but I am not aware of any other context in which the idea has been put to use in the manner proposed above. Perhaps the most common kind of context in which some notion of defeat is invoked is epistemic. Suppose, to borrow an example from Chisholm, ${ }^{31}$ that $(p) 26$ of 50 people in the room are Democrats and John is in the room. Then, if you are aware of $p$, that would give you some reason to believe that $(r)$ John is a Democrat. But suppose also that $(q) 99$ of the 100 people who voted for the measure are not Democrats and John voted for the measure. Then, if you are aware of $q$, that would give you some reason to believe that $(\sim r)$ John is not a Democrat. We might want to say, further, that $q$ defeats $p$ as far as $r$ is concerned, but what precisely would this mean? Here is one possibility, modeled on a proposal made by Chisholm himself:

(D1) $\quad q$ defeats $p$ as far as $r$ is concerned $=_{\mathrm{df}}$

(a) $p$ provides a reason to believe $r$, and

(b) (p\&q) does not provide a reason to believe $r .32$

Notice that this definition accommodates analogs to what I earlier called nullification and inversion, but it does not accommodate an analog to the milder form of defeat that I called mitigation. This is perhaps cause for some concern, but, as I see it, a far more serious concern is that defeat, so understood, does not preclude the kind of outweighing or counterbalancing with which, we have been assuming, it is to be contrasted. Let us assign numbers (once again plucked out of thin air) to reflect the relative strength of the reasons provided by $p$ and $q$ and say that $p$ provides a reason of strength 1 to believe $r$, while $q$ provides a reason of strength 10 to believe $\sim r$. Then "simple summation" would yield the result that $(p \& q)$ does not provide a reason to believe $r$ (but, on the contrary, provides a reason to believe $\sim r$ ). Hence (D1) does not capture a concept of defeat that is analogous to the concept with which we have been concerned up until now.

The same point can be made in another context, this time an ethical one. Suppose, once again to borrow an example from Chisholm, ${ }^{33}$ that $(p)$ John is mildly ill and Jane can help him and (q) Jim is seriously ill and Jane can help him but she cannot help both him and John; and let $r$ now be, not a proposition, but the action of Jane's helping John. We might want to say that $q$ defeats $p$ as far as $r$ is concerned, understanding this as follows:

$$
q \text { defeats } p \text { as far as } r \text { is concerned }=_{\mathrm{df}}
$$

${ }^{31}$ Chisholm (1989: 54-55), with some changes.

32 Cf. Chisholm (1989: 55, D6).

33 Chisholm (1989: 57), with some changes. 
(a) $p$ provides a reason to do $r$, and

(b) $(p \& q)$ does not provide a reason to do $r$.

Again, this definition is modeled (a little more loosely, this time) on one that Chisholm himself gives, ${ }^{34}$ and again it accommodates analogs to nullification and inversion but not to mitigation. But also, and importantly, once again it does not preclude the kind of outweighing or counterbalancing with which we have been supposing defeat is to be contrasted. On the contrary, it accommodates the very sort of balancing operation that lies at the heart of Ross's theory of moral obligation. ${ }^{35}$

It might be said, though, that even if (D1) and (D2) are not up to the task of capturing the concept of defeat that we are concerned with, nonetheless this concept is well recognized and well respected. Let us consider another epistemic example. Suppose, to borrow an example from Lemos, ${ }^{36}$ that $(p)$ this ball looks red to you. Then, if you are aware of $p$ (as perhaps you must be), that would seem to give you some reason to believe that $(r)$ this ball is red. But suppose also that $(q)$ you have an eye disorder that makes red objects look green and green objects look red. Then, if you are aware of $q$, that gives you some reason to believe that $(\sim r)$ this ball is not red. In this case, though, we would be unlikely to want to say that the reason provided by $p$ to believe $r$ is outweighed or overridden; on the contrary, it would seem to be undercut entirely. Perhaps (D1) does not serve to mark off undercutting from overriding, but the distinction is nonetheless genuine. So, too, suppose that ( $p$ ) Jane has promised to do $r$ in order to help John, who is mildly ill, but (q) $r$ involves killing an innocent person. In such a case we might well be reluctant to say that the reason provided by $p$ that Jane has to do $r$ is outweighed or overridden; on the contrary, it seems to be undercut entirely. Perhaps (D2) does not help us draw this distinction, but it is there.

Even in the absence of a formal account of how undercutting is to be distinguished from outweighing or overriding, I think we should agree both that the distinction is genuine and that the sort of cases of undercutting just considered bring us closer to the conception of an organic unity that is supposed to be at issue in the context of Schadenfreude. Nonetheless, it does not bring us all the way, for two reasons.

First, whether we are concerned with undercutting or merely with overriding, in either case the question has to do with what it is that $p$ contributes to the epistemic justification of believing $r$ or to the moral justification of doing $r$. So, too, in the case of the relation between parts and wholes, the analogous question has to do with what it is that some proper part of a whole contributes to the final value of that whole. But this question focuses only on the value of the whole and is not concerned at all with the value, if any, of the relevant part. Yet proponents of organic unities are of course very much concerned with both values. My first point is simply that invoking some con-

${ }^{34}$ Cf. Chisholm (1989: 57, D7).

35 Ross (1930: 41).

36 Lemos (1994: 152), with some changes. 
cept of defeat that is supposed to be analogous to undercutting and to preclude outweighing or counterbalancing does nothing, in itself, to warrant assigning some value to some proper part of a whole, let alone a value that is somehow not reflected in the value of the whole.

Second, we should note that there is a certain infelicity in saying that the reason that $p$ provides for believing or doing $r$ is undercut, since this suggests that $p$ both does and does not provide such a reason. Better would be to say that the reason that $p$ would otherwise provide is undercut. Saying so would indeed be analogous to what some philosophers have had to say about organic unities. C. D. Broad, for example, says:

Obviously there is no reason to expect that there will be any simple relation between the value or disvalue of a complex whole $\ldots$ and the values or disvalues which its elements would have in isolation from each other or in other wholes. ${ }^{37}$

In a similar vein, Thomas Hurka characterizes the principle of organic unities as follows:

The intrinsic value in a whole composed of two or more parts standing in certain relations need not equal the sum of the intrinsic values those parts would have if they existed alone, or apart from those relations. ${ }^{38}$

In both cases, I have emphasized the use of "would." This emphasis serves both to underscore the close relation between the concept of undercutting with which we have been dealing and the conception of an organic unity endorsed by Broad and Hurka (a conception that would seem to rest on the sort of ontological isolationism invoked by Moore), but also to highlight a key difference between that conception and the conception that we have been working with (one that depends on the sort of intentional isolationism invoked by Chisholm and Lemos), which is not that (a) the proper parts of a whole would have certain values if they were not parts of the whole, but rather that (b) these parts do have these values despite being parts of the whole. It is not (a) that I am claiming to be odd, but (b).

b.

I have just reaffirmed that the version of the isolation method that we should seek to employ is that which Lemos calls intentional isolationism, which, in Section 3 above, I said consists in contemplating a state of the form $[x, P, t]$ as such, that is, qua having the form $[x, P, t$. When applying this method in Section 6 to a state with the particular form of [John, being pleased, $t$ ], I claimed that it seems that contemplation of such a state as such requires that we withhold any attitude of favor, indifference or disfavor toward it, on the grounds that such a state can occur not only as a part of some innocent

37 Broad (1985: 255).

38 Hurka (1998: 300). 
pleasure (which we may assume to be finally good) but also as a part of some malicious pleasure (which we have been assuming to be finally bad). Lemos has objected that reaching this verdict on these grounds constitutes a misapplication of the method, though, for the reason that doing so involves not (or not only) contemplating a state of the form [John, being pleased, $t$ ] as such but rather (or also) contemplating such a state as a descendant of a state of some more specific form, such as [John, being innocently pleased, $t$ ] or [John, being maliciously pleased, $t$ ]. ${ }^{39}$ This is an important objection. Here is my response.

I do want us to focus on a state of the form [John, being pleased, $t$ ] as such. In noting that such a state can be part of a larger whole that has a form such as [John, being innocently pleased, $t$ ] or [John, being maliciously pleased, $t$, my purpose is merely to try to ensure that we do indeed focus on the form [John, being pleased, $t$ ] rather than on another form of state with which it might easily be confused, one that may be called [John, being just pleased, $t$ ]. In my book on intrinsic value, this is what I have to say about the distinction between these two state-forms:

[Consider] Schadenfreude. Even if the pleasure it contains would be good "on its own," this doesn't mean that it is good as such. Consider the particular case [of] [John, being pleased at Mary's pain, $t$ ]. A state of this form has as one of its parts a state whose form is [John, being pleased, $t$ ]. Contrast such a state with one whose form is [John, being just pleased, $t$ ], where "being just pleased" is intended to capture the idea that the pleasure at issue exists "on its own" to the extent possible. Such pleasure would presumably be neither appropriate nor inappropriate, neither deserved nor undeserved, since these would be further, morally significant facts about the pleasure whose admission would be inconsistent with the [rationale that underlies] isolationism. That is, [John, being just pleased, $t$ ] is to be understood to be the same state-form as (or at least to include) the following: [John, being pleased in a way that is neither appropriate nor inappropriate and neither deserved nor undeserved, $t]$. But then, given that the pleasure in a state of the form of [John, being pleased at Mary's pain, $t$ ] is inappropriate, it's clear that it does not have a state of the form of [John, being just pleased, $t$ ] as a part. Suppose, then, that we agreed that a state of the form of [John, being pleased at Mary's pain, $t$ ] was intrinsically bad but that one of the form of [John, being just pleased, $t$ ] was intrinsically good. So what? This provides no evidence that the former is an organic unity. Now, if we said that a state of the form of [John, being pleased, $t$ ] was intrinsically good, then we might have to admit that one whose form is [John, being pleased at Mary's pain, $t$ ] was an organic unity. But admitting that a state of the form of [John, being just pleased, $t$ ] is intrinsically good gives us no reason whatsoever for saying that one whose form is [John, being pleased, $t]$ is intrinsically good. ${ }^{40}$

Thus my noting that a state of the form [John, being pleased, $t$ ] can occur as part of a state of some more specific form such as [John, being innocently pleased, $t$ ] or [John, being maliciously pleased, $t]$ subserves, rather than violates, the method of intentional isolationism, since it helps to identify precise-

39 Lemos (2006: 79).

40 Zimmerman (2001: 141). 
ly the form of state whose contemplation as such is at issue. Of course, what I have said does not establish that a state of the form [John, being pleased, $t$ ] is evaluatively inadequate, but that was not my intention. My observations are intended merely to lend support to this claim.

c.

Lemos has also made the following objection. ${ }^{41}$ Consider again the simple version of hedonism mentioned in the last section, according to which a state such as $S 1$, which has the form [John, being pleased, $t$ ], is evaluatively inadequate. Compare $S 1$ with another state, $S 5$, whose form is [Jane, being pained, t]. If $S 1$ is evaluatively inadequate, then so too, presumably, is $S 5$. But surely $S 1$ is to be preferred to $S 5$. If that is the case, however, then, given the correlation between final value and fitting attitudes, $S 1$ and $S 5$ must be declared evaluatively adequate after all.

One response to this objection is that, in this paper at least, I have not (yet) invoked a correlation between final value and fitting attitudes; I have merely relied on there being a one-way relation from the former to the latter. In recent years, the converse relation has come under attack, due to what has come to be known as the wrong-kind-of-reason problem. ${ }^{42}$ But I do not want to rely on this response here, because in fact I do think that whatever it is fitting to favor or disfavor is good or bad, respectively, as long as "fitting" is understood in a certain way (one that I will not try to spell out here).

Another response to the objection is simply to deny that it is fitting to prefer $S 1$ to $S 5$. But I would not want to rely on this response, either, especially since we are presupposing that the simple version of hedonism is correct.

The best response is, I think, this: If $S 1$ occurs, it can only do so in virtue of some ontological ancestor that is evaluatively adequate. Call the closest such ancestor $S 1^{*}$. (Given what I said above, it follows that $S 1^{*}$ has basic final value.) So, too, if $S 5$ occurs, it can only do so in virtue of some closest evaluatively adequate ancestor, $S 5^{*}$. Now, on the simple version of hedonism, it is fitting to favor $S 1^{*}$ for its own sake and fitting to disfavor $S 5^{*}$ for its own sake. Thus it is fitting to prefer $S 1^{*}$ to $S 5^{*}$ for their own sakes. From this it follows, I think, not that it is fitting to prefer $S 1$ to $S 5$ for their own sakes, but rather that it is fitting to prefer the former to the latter for the sake of their respective ancestors. To say this is to attribute a certain non-final value to S1 and $S 5$, something that is perfectly consistent with denying that they have any final value.

d.

Organic unities have been contrasted with mere sums. Summation involves adding numbers, and I have used numbers to represent the final values of

41 Lemos (2003: 589-90)

42 See Rabinowicz and Rønnow-Rasmussen (2004) for a classic discussion. 
certain states. For example, in Section $4 \mathrm{I}$ assigned a value of -10 to $S 2$ and a value of +5 to $S 1$. Now, as I noted, these numbers were plucked out of thin air, since of course we have no precise way of measuring final value. But such use of numbers might be thought misleading, in that it suggests that, even if we do not know how precisely to measure final value, nonetheless whatever has such value has it to some precise degree. Yet there is reason to think that, in some cases at least, a state has final value only to an indeterminate degree. Consider once again an instance of Schadenfreude consisting in John's taking pleasure in Mary's pain. Even if John's pleasure has a precise duration and intensity, there is likely to be no precise duration or intensity to be attributed to Mary's (perhaps merely imagined) pain. If so, and if the final value of John's malicious pleasure depends in part on the object of that pleasure, it is hard to see how even in principle any precise number could represent this value. ${ }^{43}$ How, then, could summation work even in principle as a method of computing the final values of wholes, some of whose proper parts have final value only to an indeterminate degree?

One proposal is this:44 Even though no single number can accurately represent the final value of a state that has such value only to an indeterminate degree, nonetheless a range of numbers can do so. This range will constitute a numerical interval with upper and lower limits, and intervals are amenable to summation. ${ }^{45}$ To this proposal it might be objected (indeed, Lemos has objected) that it is not clear how to assign intervals to states with indeterminate final values in a way that accurately reflects these values. ${ }^{46}$ Of course, I agree that this is so, but what is also not clear (to me, at least) is whether this problem is theoretical or merely practical. (The question turns at least in part on how vagueness is to be understood, and I have nothing useful to offer here.)

Suppose that the problem is theoretical and that, as a result, summation cannot work even in principle as a method of computing the final values of wholes, some of whose proper parts have final value to an indeterminate degree. Then, of course, the most recent formulation of the principle of organic unities must be accepted after all. That formulation, you will recall, was this:

POU 5: The final value of a whole must not be assumed to be the same as the sum of the basic final values of those of its proper parts that have such value.

Even so, I believe that this still does not give us a reason to accept the fundamental idea with which proponents of the principle have been concerned. It is not easy to state precisely what this idea comes to, but perhaps the following will do as a rough approximation:

43 Cf. Lemos (2010: 38ff.). The problem here is analogous to that of assigning a precise number to the speckles comprised in the sense datum yielded by a single glance at a speckled hen. Cf. Chisholm (1942).

${ }^{44}$ Cf. Zimmerman (2001: 179-80).

${ }^{45}$ Let $a$ be the interval $\left[a_{1}, a_{2}\right]$ and $b$ be the interval $\left[b_{1}, b_{2}\right]$. Then $a+b=\left[a_{1}+b_{1}, a_{2}+b_{2}\right]$. See Kaufmann and Gupta (1991: 2-3).

46 Lemos (2010: 40). 
POU 6: The final value of a whole must not be assumed to be proportionate to the basic final values of those of its proper parts that have such value.

Again, the conception of an organic unity must of course be revised accordingly:

OU 6: $x$ is an organic unity $=_{\mathrm{df}}$ the final value of $x$ is not proportionate to the basic final values of those of its proper parts that have such value.

Even if summation cannot serve to capture every kind of proportionality that might obtain between the final value of a whole and the basic final values of those of its proper parts that have such value, it might nonetheless be the case that some such proportionality always obtains. At least, the phenomenon of Schadenfreude provides us no reason to believe otherwise.

\section{Mixed Emotions}

I have conducted an extended inquiry into the final value of Schadenfreude and have argued that there is no need to think that such pleasure constitutes an organic unity. The basic insight (as I see it) underlying my account is that, when such pleasure occurs, there is notbing to celebrate. The attitude that is fitting for anyone who contemplates it as such is an unfavorable one, and there is no reason to temper this attitude in any way when one contemplates any part of it. But this observation, even if correct, raises the question of what we should say when it seems that it is fitting to have an ambivalent attitude when contemplating some state. Might not such a state sometimes constitute an organic unity?

One prominent type of case that might seem to fit the bill involves, not a positive response to something evil (as when John takes pleasure in Mary's pain), but a negative response to something evil. Consider Mitleid. This involves being pained at another person's (perhaps only imagined) pain. Or consider deserved punishment (if such exists). This involves undergoing suffering for some transgression. Or consider righteous indignation, and so on. It is often said that such cases constitute organic unities, since the negative response (the pain, the suffering), though bad in itself, makes the overall situation better than it would be without the response (even if perhaps not as good as it would be if whatever evil prompted the response had not occurred in the first place). ${ }^{47}$ Moreover - and this is the key point - in such cases it seems clear that, not only is it fitting to have a certain attitude toward the overall situation as such, it is also fitting to have some other attitude toward that proper part of the overall situation that consists in the negative response in question. Contemplation of it as such warrants a decidedly less favorable attitude. In such a case, then, the relatively favorable attitude toward the

47 Cf. Moore (1903: 215), (1993: 263); Chisholm (1986: 78); Lemos (1994: 36-38); Hurka (1998: 309-11). 
whole should be tempered by a far less favorable attitude toward one of its proper parts, and so such cases cannot be dealt with in the same sort of way in which I have proposed that we deal with Schadenfreude.

For the sake of illustration, let us focus on Mitleid. Consider again S5, which has the form [Jane, being pained, $t$ ]. Suppose that it occurs in virtue of $S 6$, whose form is [Jane, being pained $d_{d=10, i=5, t}$ ], which in turn occurs in virtue of $S 7$, whose form is [Jane, being pained $d_{d=10, i=5}$ at Mary's pain, $t$ ]. And let us now assume, for the sake of argument, that $S 7$, being an instance of compassion, is finally good. (This assumption, which many appear prepared to make, ${ }^{48}$ is one that $\mathrm{I}$ in fact reject, ${ }^{49}$ but it serves for dramatic purposes.) Given the relation mentioned above between final value and fitting attitudes, it would follow that contemplation of $S 7$ as such would require having a favorable attitude toward it for its own sake. But here, in contrast to what I have claimed about Schadenfreude, it might well seem that another attitude would also be fitting, one that tempers the favorable attitude. In particular, it might seem that contemplation of $S 6$ as such would require having an unfavorable attitude toward it for its own sake. If so, what I have said about Schadenfreude cannot be applied, mutatis mutandis, to Mitleid.

The claim that Mitleid calls for ambivalence might be disputed. ${ }^{50}$ Indeed, in my book on intrinsic value, I implicitly treat it as analogous to Schadenfreude, that is, as a whole all of whose parts are evaluatively inadequate. But that now seems to me a mistake, and I am prepared to accept, for the sake of argument, that $S 6$ is evaluatively adequate - indeed, that it is finally bad and, moreover, that it is worse than $S 7$. The question remains whether this concession requires also conceding that $S 7$ is an organic unity. I cannot see that it does. Even if $S 7$ is finally good while $S 6$ is finally bad, $S 7$ does not constitute an organic unity as long as it has some other part whose value counterbalances the value of S6. An obvious possible candidate here is a state of the form [Jane, experiencing an appropriate emotion, $t$ ], since it seems clear that it is the appropriateness of Jane's response to Mary's pain that prompts the verdict that her compassion is to be applauded. Of course, whether such a state counts as being a part of $S 7$ depends in part on just how the part-whole relation is to be conceived - an issue that I addressed in Section 4, above. On the account of this relation that I have proposed, it is perhaps not clear whether a state, such as S7, of the form [Jane, being pained $_{d=10, i=5}$ at Mary's pain, $t$ ] will have as a part a state whose form is [Jane, experiencing an appropriate emotion, $t]$. Even so, what is clear is, first, that a state of the form [Jane, being appropriately pained $_{\mathrm{d}=10, \mathrm{i}=5}$ at Mary's pain, $t$ ] will have as a part a state whose form is [Jane, experiencing an appropriate emotion, $t$, and, second, that, on the assumption that Mitleid is to be applauded for its appropriateness, a state such as $S 7$ will always have a state of

48 See, e.g., Moore (1903/1993, ch. 6); Ross (1930, ch. 5); Chisholm (1986: 66); Lemos (1994: 74).

49 See Zimmerman (2001: 207-8).

50 Cf. Olson (2004: 47). 
the form [Jane, being appropriately pained $\mathrm{d}_{\mathrm{d}=10, \mathrm{i}=5}$ at Mary's pain, $t$ ] as an ontological ancestor.

Even if a state of the form [Jane, experiencing an appropriate emotion, $t$ ] is a valuable part of $S 7$, the question of course still remains whether it has a value that can be balanced against the value of $S 6$ in such a way as to account for the final value of $S 7$. If not, then we still have an organic unity on our hands. Here I will only say that, although I have no argument to give in favor of the claim that such a case involves proportionality between the value of the whole and the values of its proper parts, I also know of no good reason to deny this claim.

\section{Anticlimactic Conclusion}

I have argued that neither Schadenfreude nor Mitleid provides a clear case of an organic unity. That of course does not mean that they are clearly not cases of organic unities, let alone that there are no organic unities of other sorts. The literature is full of other examples of alleged organic unities, involving such matters as the bonum variationis, the bonum progressionis, beauty, courage and more. ${ }^{51}$ Are these genuine organic unities, or can their final values be accounted for in some other way? My sense is that their values can all be accounted for by appealing either to evaluative inadequacy (as in the case of Schadenfreude) or to proportionality (as in the case of Mitleid), but whether this is the case is of course open to debate.

This is perhaps a disappointingly weak conclusion, since it leaves unresolved the question of whether organic unities exist. It is nonetheless a conclusion worth noting. Moore says repeatedly that it is "certain" that organic unities exist, 52 and that this (alleged) fact is "one of the most important which Ethics has to recognize," since otherwise "the grossest errors will be committed." ${ }_{53}$ I hope that the foregoing suffices to show that such claims would seem, in the absence of further argument, to be badly overblown.

I should confess, however, that there may be still more disappointment to come; for there is the further question of whether anything of real significance turns on whether the principle of organic unities is accepted or rejected, and I am not sure that it does. Both proponents and opponents of the principle typically accept the same evaluations of the wholes in question, and this is where the practical implications lie. (Those theodicists who hold that this is the best of all possible worlds are of course an exception to this general rule.) Moreover, in the absence of a cogent argument against the very possibility of organic unities, it is unclear just what theoretical significance is to be attributed to the debate over whether the principle of organic unities is true. It is sometimes said - indeed, I myself have said - that finding a principled way to reject this principle would facilitate our computation of final value, but, in all honesty, this claim, too, seems badly overblown. Unless and

${ }^{51}$ Cf. Chisholm (1986, ch. 7); Lemos (1994: 34ff.).

52 Moore (1903: 28), (1993: 79).

53 Moore (1903: 36), (1993: 87). 
until those states that have basic final value are identified and evaluated with some respectable degree of precision - an accomplishment that promises to remain forever elusive - evaluating those wholes that comprise them will continue to be a matter of intuition rather than computation..$^{54}$

Michael J. Zimmerman

Department of Philosophy

University of North Carolina at Greensboro

m_zimme2@uncg.edu

54 An earlier draft of this paper was presented at the Kline Workshop on Value Holism, held at the University of Missouri in Columbia in April 2014. I am grateful for the many and various comments made by those who attended the workshop, and I am especially grateful for the trenchant criticism provided by Noah Lemos, Peter Vallentyne and Paul Weirich. I am grateful also for the helpful comments of two anonymous referees for this journal. 


\section{References}

Brännmark, J. (2001) “Good Lives: Parts and Wholes,” American Philosophical Quarterly 38: 221-31.

Brentano, F. (1969) The Origin of Our Knowledge of Right and Wrong, London: Routledge and Kegan Paul. Broad, C. D. (1985) Ethics, Dordrecht: Martinus Nijhoff. (1930) Five Types of Ethical Theory, London: Kegan Paul, Trench, Trubner.

Bykvist, K. (2009) “No Good Fit: Why the Fitting Attitude Analysis of Value Fails," Mind 118: 1-30.

Chisholm, R. M. (1989) Theory of Knowledge, 3rd edition, Englewood Cliffs: Prentice Hall. (1986) Brentano and Intrinsic V alue, Cambridge: Cambridge University Press.

_ (1968-69) "The Defeat of Good and Evil," Proceedings and Addresses of the American Philosophical Association 42: 21-38. (1942) "The Problem of the Speckled Hen," Mind 51: 368-73.

Dancy, J. (2004) Ethics Without Principles, Oxford: Clarendon Press.

Davidson, D. (1980) Essays on Actions and Events, Oxford: Clarendon Press.

Ewing, A. C. (1948) The Definition of Good, New York: Macmillan and Co.

Feldman, F. (2000) “Basic Intrinsic Value,” Philosophical Studies 99: 319-46.

Harman, G. (1967) “Toward a Theory of Intrinsic Value,” Journal of Philosophy 64: 792-804.

Hurka, T. (1998) “Two Kinds of Organic Unity," Journal of Ethics 2: 299-320.

Kagan, S. (1998) "Rethinking Intrinsic Value," Journal of Ethics 2: 277-97.

Kaufmann, A. and Gupta, M. M. (1991) Introduction to Fuzzy Arithmetic, New York: Van Nostrand Reinhold.

Kim, J. (1976) "Events as Property Exemplifications," in M. Brand and D. Walton, eds., Action Theory, Dordrecht: D. Reidel, pp. 159-77.

Lemos, N. M. (2010) "Summation, Variety, and Indeterminate Value," Ethical Theory and Moral Practice 13: 33-44. (2006) "Indeterminate Value, Basic Value, and Summation," in K. McDaniel, et al., eds., The Good, the Right, Life and Death, Aldershot: Ashgate, pp. 71-81.

(2003) "Review: The Nature of Intrinsic Value," Mind 112: 587-90. (1994) Intrinsic V alue, Cambridge: Cambridge University Press.

Moore, G. E. (1993) Principia Ethica, revised edition, Cambridge: Cambridge University Press. (1922) Philosophical Studies, London: Routledge and Kegan Paul. (1903) Principia Ethica, Cambridge: Cambridge University Press.

Olson, J. (2004) "Intrinsicalism and Conditionalism about Final Value," Ethical Theory and Moral Practice $7: 31-52$.

Quinn, W. S. (1974) “Theories of Intrinsic Value,” American Philosophical Quarterly 11: 123-32.

Rabinowicz, W. and Rønnow-Rasmussen, T. (2004) “The Strike of the Demon," Ethics 114: 391423. (1999) "A Distinction in Value: Intrinsic and For Its Own Sake," Proceedings of the Aristotelian Society 100: 33-52.

Ross, W. D. (1939) Foundations of Ethics, Oxford: Oxford University Press. (1930) The Right and the Good, Oxford: Oxford University Press.

Thomson, J. J. (1977) Acts and Other Events, Ithaca: Cornell University Press.

Zimmerman, M. J. (2001) The Nature of Intrinsic V alue, Lanham: Rowman and Littlefield. 